\title{
Subduction-controlled mantle flow and seismic anisotropy in South America
}

\author{
Jiashun $\mathrm{Hu}^{\mathrm{a}, *}$, Manuele Faccenda ${ }^{\mathrm{b}}$, Lijun $\mathrm{Liu}^{\mathrm{a}}$ \\ a Department of Geology, University of Illinois at Urbana-Champaign, 605 E. Springfield Ave, Champaign, IL 61820, USA \\ b Dipartimento di Geoscienze, Università di Padova, 35131, Padova, Italy
}

\section{A R T I C L E I N F O}

\section{Article history:}

Received 21 January 2017

Received in revised form 12 April 2017

Accepted 13 April 2017

Available online $\mathrm{xxxx}$

Editor: P. Shearer

\section{Keywords:}

South America

shear wave splitting

surface wave anisotropy

LPO

subduction

mantle flow

\begin{abstract}
A B S T R A C T
Seismic anisotropy records both the past and present deformation inside the solid Earth. In the mantle, seismic anisotropy is mainly attributed to the lattice preferred orientation (LPO) of mineral fabrics, caused by the shear deformation due to mantle flow. However, contributions from different tectonic processes remain debated, and a single geodynamic model that simultaneously explains the observed mantle structures and various seismic anisotropy measurements is still lacking. Here, we present a model for the Cenozoic subduction history in South America using a geodynamic simulation constrained by both past plate reconstructions and present mantle seismic structures. With a recently developed software package DRexS, we further predict azimuthal seismic anisotropy at different depths and generate synthetic shear wave splitting (SWS) measurements using the resulting mantle flow. Our results provide a good match to both depth-dependent surface wave anisotropy and various land-based SWS records. We find that the dominant control on seismic anisotropy in South America comes from subduction-induced mantle flow, where anisotropy below the subducting Nazca Plate aligns with plate-motion-induced Couette flow and that below the overriding South American Plate follows slab-induced Poiseuille flow. This large-scale mantle flow can be diverted by secondary slabs, such as that below the Antilles subduction zone. In contrast, the contribution to SWS from fossil continental anisotropy and from the effects due to mantle flow modulation by lithosphere thickness variation are minor. Upper-mantle fast seismic anomalies beneath the southern Atlantic margin should have close-to-neutral buoyancy in order to satisfy the observed seismic anisotropy.
\end{abstract}

Published by Elsevier B.V.

\section{Introduction}

Seismic anisotropy is defined as the dependence of wave speed on the direction of seismic polarization and wave propagation. It has been generally attributed to lattice preferred orientation (LPO) of anisotropic minerals (Nicolas and Christensen, 1987; Zhang and Karato, 1995; Kaminski and Ribe, 2001) or shape preferred orientation (SPO) of locally concentrated isotropic materials with distinct elastic properties (Mainprice and Nicolas, 1989; Kendall and Silver, 1996). Since the first observation of seismic anisotropy made by Hess (1964), an enormous amount of research has been done both globally and regionally. However, the origin of seismic anisotropy remains debated and the proposed causes of anisotropy vary from place to place (Long and Silver, 2009; Long and Becker, 2010).

By analyzing shear wave splitting (SWS), Silver and Chan (1991) and Silver (1996) argued that the fast-polarization direction in sta-

\footnotetext{
* Corresponding author.

E-mail address: jhu16@illinois.edu (J. Hu).
}

ble continents correlated well with tectonic structures in the crust, implying that "frozen anisotropy" (e.g. Isma1l and Mainprice, 1998) imprinted by past crustal deformation was the dominant source. This idea was adopted in some regional studies, such as in SE Brazil (James and Assumpção, 1996) and Fennoscandia (Vecsey et al., 2007; Eken et al., 2010). In contrast, Vinnik et al. (1992) and Fouch et al. (2000) analyzed SKS splitting in North America and argued that most of the anisotropy is parallel to the plate motion. Recent studies further invoked the role of lithosphere thickness variation in the formation of SWS (Fouch et al., 2000; Assumpção et al., 2006; Wang et al., 2008; Assumpção et al., 2011; Miller and Becker, 2012; Foster et al., 2014). For example, Fouch et al. (2000) and Wang et al. (2008) related the SWS to mantle flow perturbed by the North American Craton and Colorado Plateau. Similarly, Assumpção et al. (2006, 2011) and Miller and Becker (2012) proposed the thick continental roots in South America modulate the anisotropy pattern by diverting mantle flow below southeastern Brazil and northern South America, respectively. However, SWS measurements have little depth resolution 


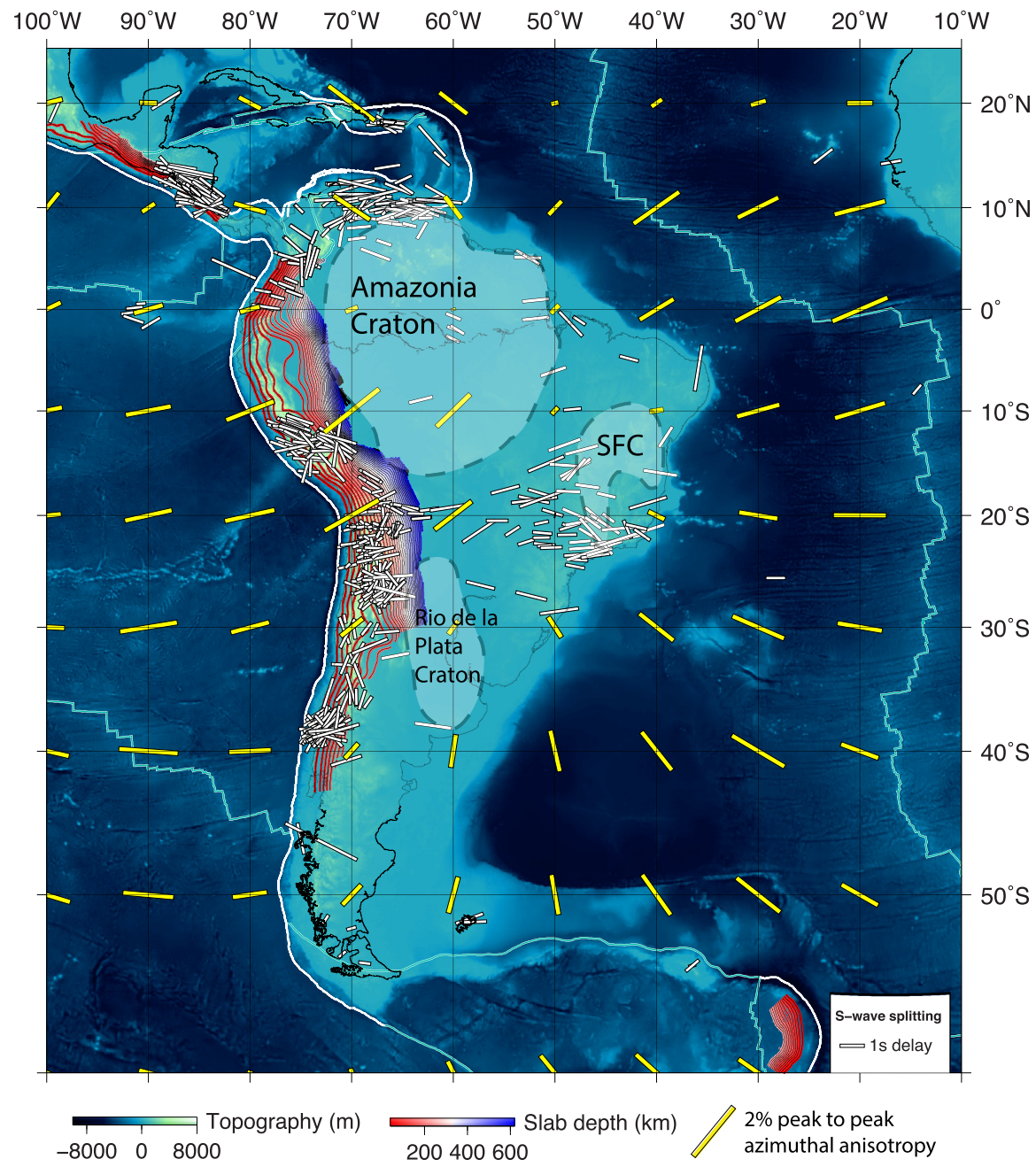

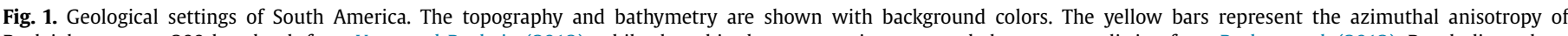

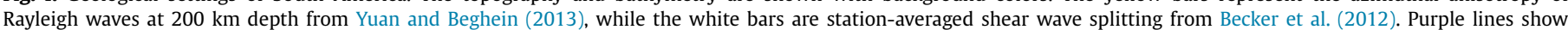

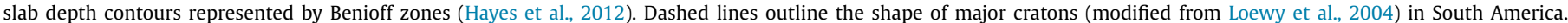
SFC: Sao Francisco Craton. (For interpretation of the references to color in this figure legend, the reader is referred to the web version of this article.)

(Favier and Chevrot, 2003), which renders the associated tectonic interpretation non-unique.

Relative to SWS, surface wave and normal mode studies could better resolve the depth distribution of seismic anisotropy (Gung et al., 2003; Debayle et al., 2005; Marone and Romanowicz, 2007; Yuan and Beghein, 2013). For example, Gung et al. (2003) measured radial anisotropy at depths from $250-400 \mathrm{~km}$ that reconciles the discrepancy of different isotropic tomography models. Debayle et al. (2005) observed significant azimuthal anisotropy beneath Australia at $175-300 \mathrm{~km}$ depths that correlates well with the present plate motion. By simultaneously matching waveforms and shear wave splitting data, Marone and Romanowicz (2007) proposed a layered anisotropy structure in the cratonic part of North America, implying contributions from both the lithosphere and the underlying asthenosphere. Although with a likely different origin, a layered anisotropy structure was also observed in the Pacific (Smith et al., 2004; Beghein et al., 2014), where the Pacific upper lithosphere records the paleospreading direction, while anisotropy at greater depth reflects present-day plate motion. However, this interpretation was challenged by a more recent study by Lin et al. (2016), who showed that the anisotropy at asthenosphere depth has a different fast direction from that due to present plate motion, and they attributed this to pressure-driven channel flow beneath the ocean basin (e.g., Höink et al., 2012).
The diverse observations of seismic anisotropy have propelled many geodynamic modeling efforts (Conrad et al., 2007; Conrad and Behn, 2010; Faccenda et al., 2008; Faccenda and Capitanio, 2013; Becker et al., 2003, 2006a, 2006b, 2014). Conrad et al. (2007) and Becker et al. $(2003,2014)$ built global mantle convection models based on seismic tomography. They demonstrated that LPO due to density-driven mantle flow matches the observation of asthenospheric anisotropy beneath ocean basins, a better prediction than that only due to plate motions. By matching the SWS data at the South American-Caribbean plate margin, Miller and Becker (2012) showed that mantle flow in the region can be deflected by cratonic keels and nearby subduction zones, suggesting a significant effect of cratons on SWS. However, these studies only utilized instantaneous mantle flow models when calculating LPO. In theory, a time-dependent flow is needed to accurately predict seismic anisotropy, due to the response of anisotropic minerals to the cumulative strain (Ribe, 1992). Recently, such efforts have been made to account for both the deformation history and the full 3D strain field (Faccenda and Capitanio, 2012, 2013).

In this paper, we simultaneously investigate the origin of surface wave anisotropy and SWS data in South America (Fig. 1). We present a data-oriented convection model that simulates South American subduction since the Mid-Cretaceous. Then we use the resulting Cenozoic mantle flow to generate synthetic seismic anisotropy that is subsequently compared with SWS measure- 


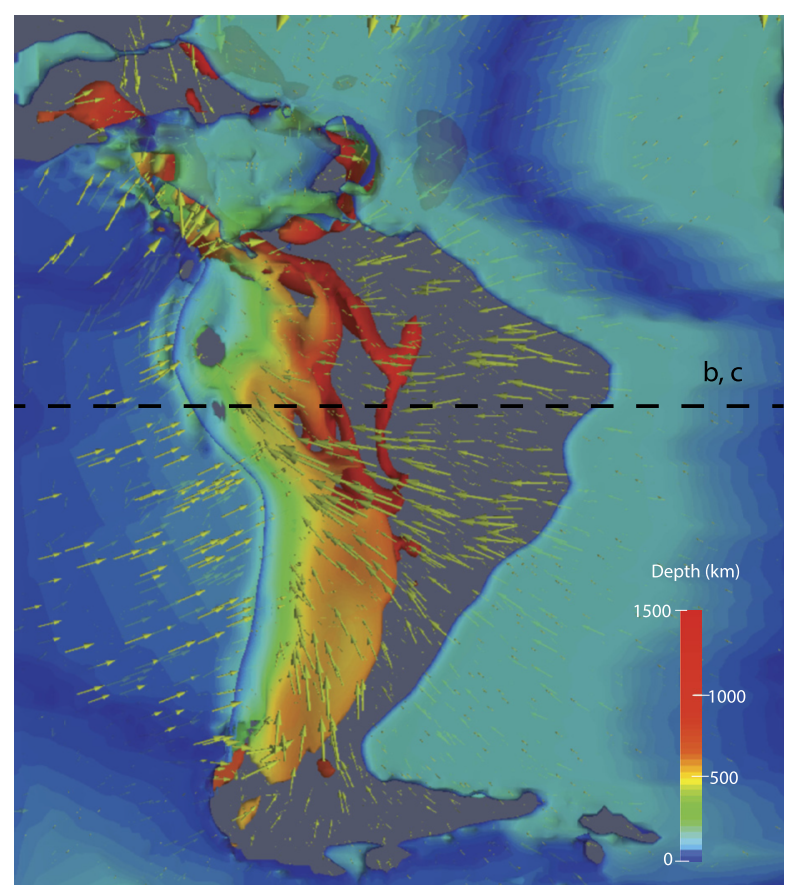

b
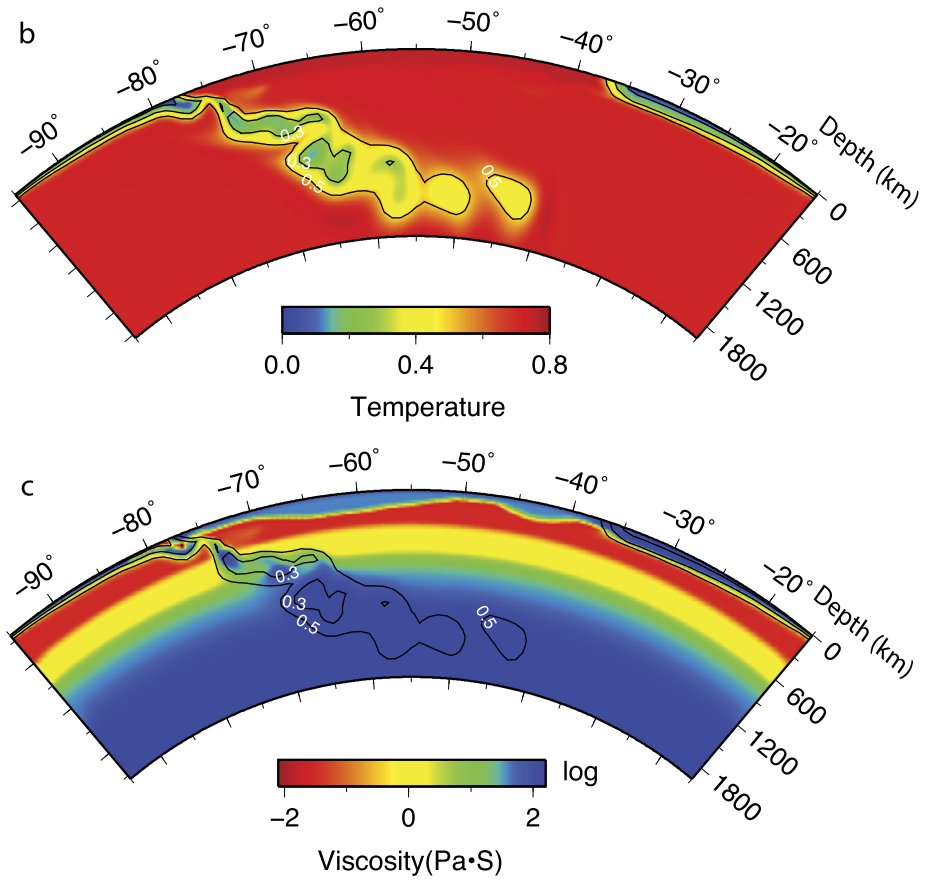

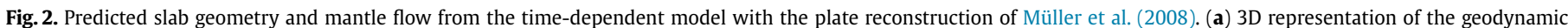

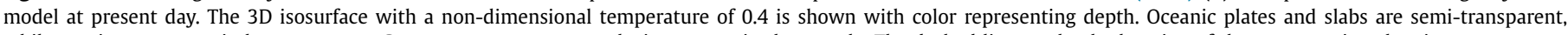

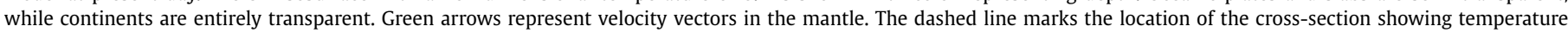

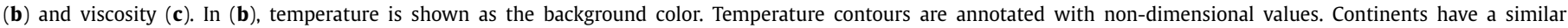

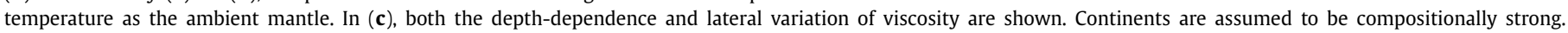
(For interpretation of the references to color in this figure legend, the reader is referred to the web version of this article.)

ments and surface wave anisotropy (Fig. 1). This new approach represents several potential advances from earlier modeling efforts. First, our model utilizes time-dependent rather than instantaneous mantle flow, and therefore is more appropriate for the prediction of LPO, which is intrinsically evolving with time. Second, we employ a more accurate anisotropy generator by upgrading the 3-D DRex code implemented by Faccenda and Capitanio (2013) to further consider the 4-D deformation history within a spherical Earth; this is more accurate than earlier anisotropy approximations using infinite strain axes (ISA) or finite strain ellipsoid (FSE). Third, the subduction history and resulting slab geometry in our model are tightly constrained by past plate reconstructions and present mantle structures (Hu et al., 2016; $\mathrm{Hu}$ and Liu, 2016); the resulting mantle flow should better represent the real Earth, compared to that estimated based on tomography images or parameterized slab geometry.

Consequently, our new approach has the potential to reconcile existing uncertainties and to discover new insights on the origin of seismic anisotropy. Our results reveal a multi-scale mantle flow pattern that is confirmed by the seismic anisotropy data. At the plate-scale, a broad upper mantle poloidal flow originated from both sides of the subducting Nazca slab dominates the entire region, as is opposed to the previously suggested plate-motiondominant origin. At local scales, this flow is modulated by the secondary slab below the Antilles trench and by large-sized cratonic keels within the continent, although the effect of the latter is relatively minor to fit SWS. Both the predicted depth-dependent anisotropy within the region and the predicted SWS on land match observation very well, with the exception being SWS along the Nazca trench where the fit is marginal. Therefore, our study suggests a subduction-dominant mechanism for mantle deformation in South America.

\section{Methodology}

In this section, we describe the methods used to generate mantle flow and to calculate seismic anisotropy. These involve three open-source software packages, including 1) Citcoms (Tan et al., 2006; Zhong et al., 2008) that simulates mantle convection using data assimilation algorithms (Liu and Stegman, 2011; Hu et al., 2016), 2) DRexS, an upgraded version of the original 2-D DRex (Kaminski et al., 2004) and the recent version 3-D Rex (Faccenda and Capitanio, 2013), that now also calculates LPO based on time-dependent mantle flow in spherical geometry, as well as 3) FSTRACK (Becker, 2006), which is used to predict SKS with the elastic tensors produced by DRexS.

\subsection{Calculating time-dependent mantle flow}

Following the modeling approach used in Hu et al. (2016), we simulate the South American subduction history since 100 Ma with data assimilation techniques. Both boundary conditions and main tectonic features assimilated in the subduction model were discussed in Hu et al. (2016) (Fig. 2). To reiterate, we take the plate motion history from a recent plate reconstruction (either Müller et al., 2008 or Müller et al., 2016; Fig. S2) as the surface velocity boundary condition, and use the seafloor age from the same reconstruction to update the thermal structure of the oceanic lithosphere assuming a plate model (Hasterok, 2013). The initial condition is a mantle with a uniform temperature, with a prescribed plate thermal structure on top. Over time, oceanic plates subduct following the observed plate motion, and eventually lead to a complex mantle structure as observed today (Hu et al., 2016).

The viscosity in the model is temperature-, pressure- and composition-dependent, with a pre-factor following a radial viscosity profile shown in Fig. S3b. This profile includes a weak asthenosphere and a strong middle lower mantle as suggested 

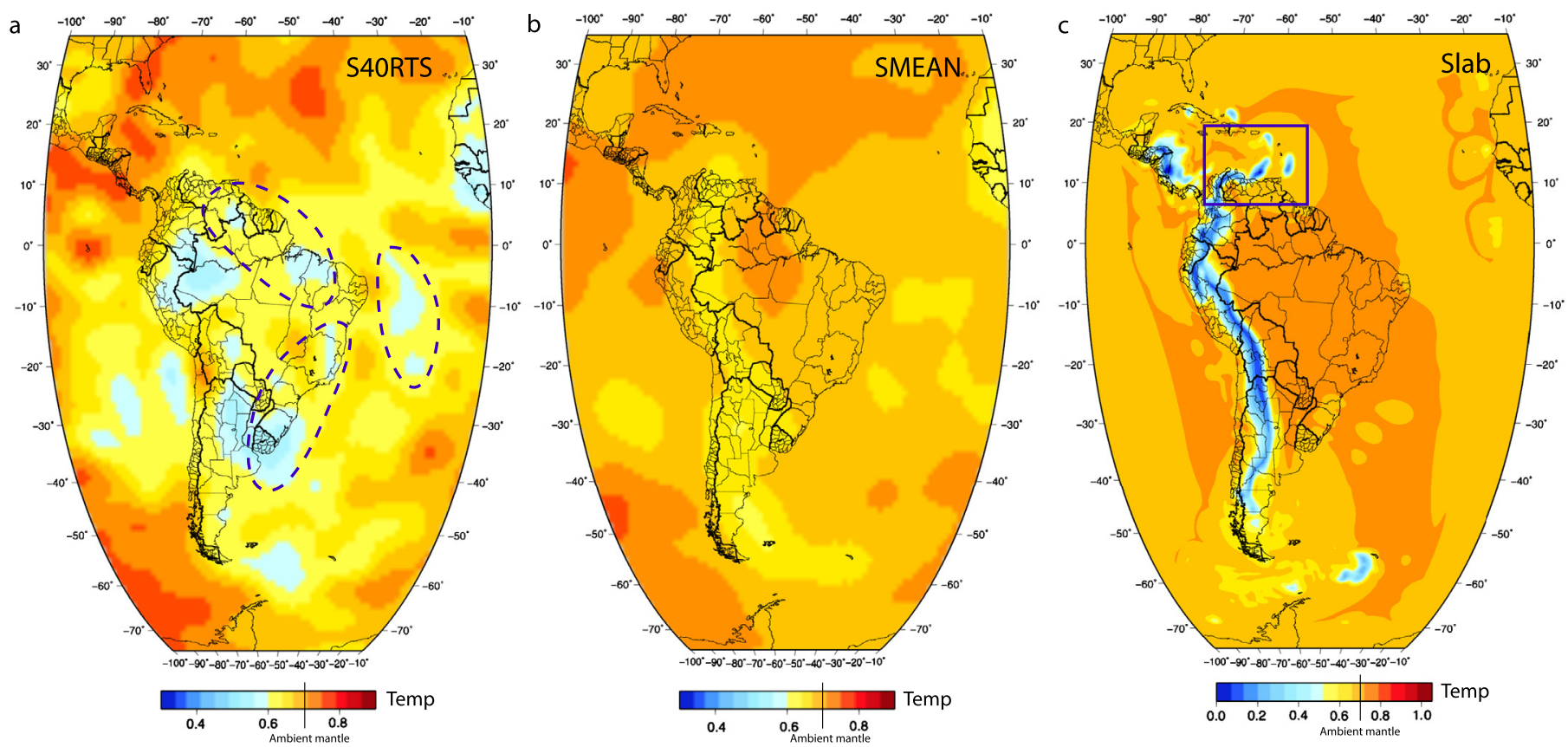

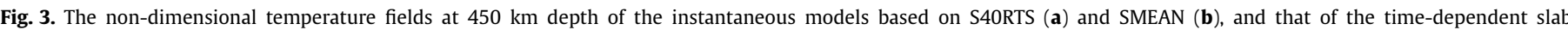

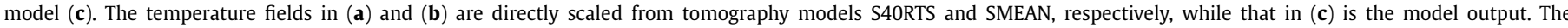

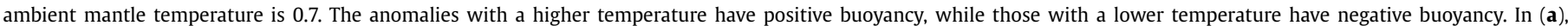

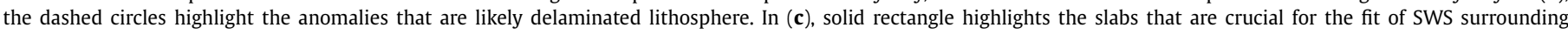
the Caribbean Plate.

by recent petrological experiment (Marquardt and Miyagi, 2015) and geophysical inversions (Rudolph et al., 2015). We use compositional tracers to define high-viscosity continent and cratons (Fig. 2c; Fig. S3a). Geometry of the cratons is based on Loewy et al. (2004). The maximum thickness of cratons is assumed to be $250 \mathrm{~km}$, while the rest of the continent is $100 \mathrm{~km}$ thick (Fig. S3a). Both the continent and the cratons are 1000 times stronger than the asthenosphere, which allows them to persist over the subduction history. To test the effect of cratons on SWS, we also run models without cratons for comparison. In these models, a uniform $100 \mathrm{~km}$-thick continent is assumed.

Compared to Hu et al. (2016), this study covers a larger geographic region along the north-south direction, which now extends from $75^{\circ} \mathrm{S}$ to $35^{\circ} \mathrm{N}$, while keeping the same east-west $\left(260^{\circ} \mathrm{W}\right.$ to $350^{\circ} \mathrm{W}$ ) and vertical (down to $2900 \mathrm{~km}$ depth) dimensions. This allows us to further consider the anisotropy within the Caribbean Sea that was close to the edge of the previous model. We also increased the number of grids from 257 to 513 in the north-south dimension, where the increased resolution $\left(\sim 23 \times 27 \times 8 \mathrm{~km}^{3}\right)$ allows us to better resolve the variation of mantle flow along the Nazca trench and the east Caribbean trench.

In order to place this work in the context of previous studies (Conrad et al., 2007; Conrad and Behn, 2010; Becker et al., 2006a, 2006b, 2014), we further construct tomography-based instantaneous models, with imposed plate motions. In these models, we only consider density anomalies below $300 \mathrm{~km}$, which are scaled from the tomography model S40RTS (Ritsema et al., 2011) (Fig. 3a) or SMEAN (Becker and Boschi, 2002) (Fig. 3b), similar to previous studies. In these models, the same geometry of continent and cratons (Fig. S3a) as that in the slab models is used.

\subsection{Computing strain-induced $L P O$}

The development of LPO in the upper mantle depends on several deformation mechanisms, including plastic deformation, dynamic recrystallization, and grain-boundary sliding (Kaminski et al., 2004). Here, we use the kinematic model of Kaminski et al.
(2004) that incorporates these deformation mechanisms to compute the LPO using the constrained mantle flow histories.

The computation of LPO (e.g. in Fig. S1a) is carried out by a FORTRAN code DRexS which is modified from 3-D DRex (Faccenda and Capitanio, 2013). DRexS is able to calculate LPO in spherical coordinates, allowing a seamless communication with mantle convection models using CitcomS. In addition, it supports hybrid MPI and OpenMP. This significantly speeds up the computation and enables the usage of the full memory across many computation nodes, which allow tracking elastic properties of the mantle with a relatively high resolution as presented here.

To calculate LPO, the code first initializes a large number of Lagrangian particles representing mineral aggregates. The horizontal distance between these particles is $50 \mathrm{~km}$ and the vertical distance is $30 \mathrm{~km}$. Each particle consists of 1000 crystals with 70\% A-type olivine and $30 \%$ enstatite that are representative of a harzburgitic upper mantle $(0-410 \mathrm{~km})$ composition. Initially, these crystals are randomly oriented, forming an isotropic mantle. These particles are then advected in the evolving mantle flow field. The code solves the advection equation with a fourth-order Runge-Kutta scheme. As the mineral aggregates advect in the mantle, the orientations of these crystals change in response to shear deformation, generating LPO. When reaching the present day, the elastic tensor of each mineral aggregate is computed using a Voigt average of all crystal elastic tensors in the aggregate scaled by their volume fractions. With the projection method of Browaeys and Chevrot (2004), the optimized transverse isotropy is extracted from the full elastic tensor. As transverse isotropy dominates the anisotropic part of the full elastic tensor in upper mantle crystal aggregates, the magnitude and orientation of the symmetry axis of the transverse isotropy, i.e. TI axis, outline the configuration of the elastic anisotropy. Once the mineral aggregates advect below the depths of the $410-\mathrm{km}$ phase transformation, the LPO of these aggregates will be reset to random orientations.

The TI axis of upper mantle aggregates approximately coincides with the direction of maximum stretching, fastest seismic velocity and little SWS (Faccenda and Capitanio, 2013). When sub- 

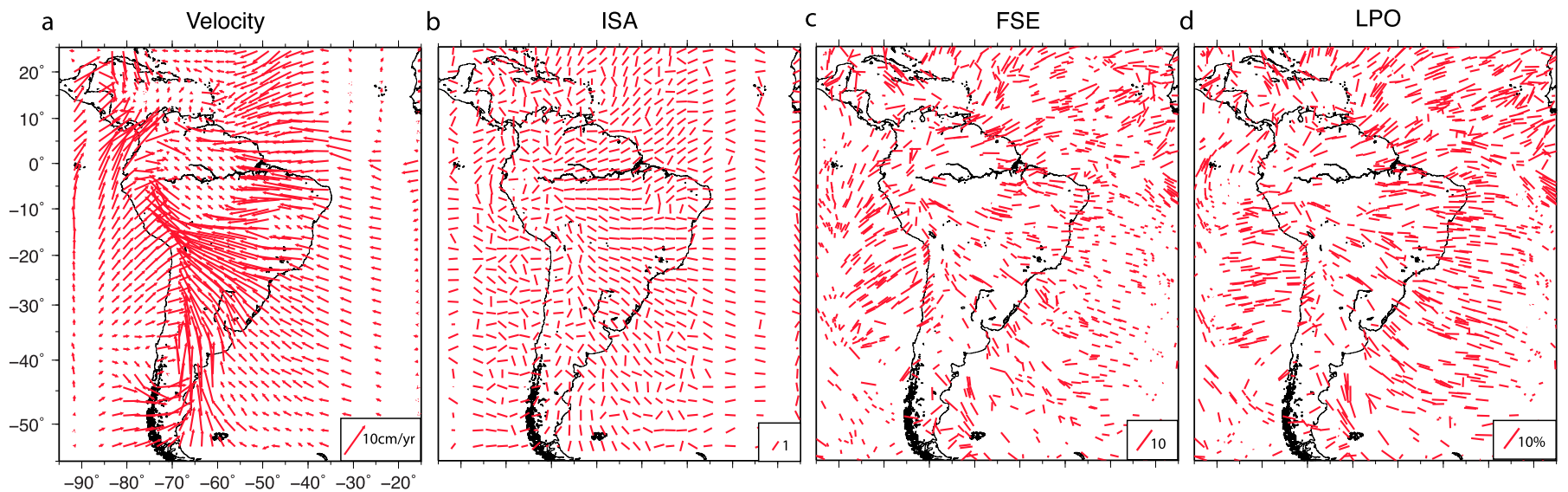

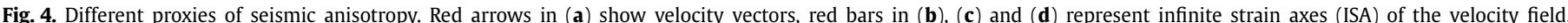

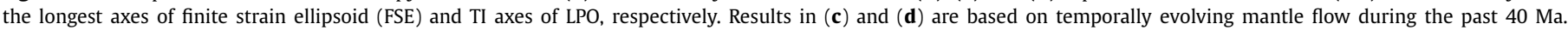

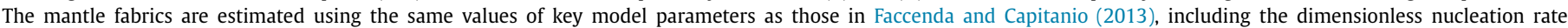

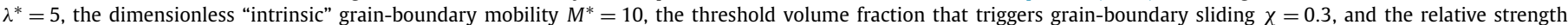

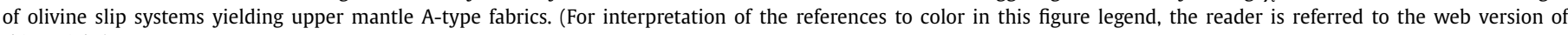
this article.)

horizontal, such TI axes define the orientation of the SKS fast component and maximum SWS is expected. Conversely, sub-vertical TI axes yield little or no SWS for SKS waves. For all the timedependent models, we take the evolving mantle flow fields from $40 \mathrm{Ma}$ to the present day to compute LPO. For the instantaneous models, we use the present-day mantle flow to represent the flow fields in the past $40 \mathrm{Myr}$, i.e. assuming the mantle flow field does not change since $40 \mathrm{Ma}$, and then take them as input to compute LPO.

\subsection{Predicting SKS splitting}

Using the software package FSTRACK (Becker et al., 2006b), we further compute synthetic SKS splitting at the same sites where SKS measurements are made. The code first computes a synthetic seismogram and then uses the cross-correlation method (Menke and Levin, 2003) to determine SKS splitting. The cross-correlation method is similar to the transverse-component-minimization method (Silver and Chan, 1991). It utilizes a grid-search approach to determine the splitting parameters $(\Phi, \delta t)$, where $\Phi$ represents fast direction and $\delta t$ splitting time. However, it is worth noting that in the presence of complex anisotropy, the two methods may disagree (Long and van der Hilst, 2005), and both of them may be inaccurate in certain situations (Long and Silver, 2009). In principle, the code should employ the same method to compute SKS as that used in observation. However, due to difficulties in classifying the SKS measurements calculated with different methods and in implementing all these methods including multichannel (Chevrot, 2000) and cross-convolution (Menke and Levin, 2003), the code FSTRACK simply uses the cross-correlation method for all the calculations. This approach is proved to be more robust compared with the transverse-component-minimization method (Vecsey et al., 2008).

To predict SKS splitting (Fig. S1b), the code first gathers the elastic tensors of all upper mantle mineral aggregates from the output of DRexS that are located within a horizontal distance of $50 \mathrm{~km}$ from each virtual seismic station and stack them into distinct layers below the station. Then it computes the harmonic response of an incident plane wave to the horizontal layers, assuming an incident angle of $5^{\circ}$ that is typical for SKS waves. These harmonic responses are computed over a range of frequencies from 0 to $25 \mathrm{~Hz}$ and are summed up to obtain a pulse of seismogram via inverse Fourier transformation. The synthetic seismogram is further filtered to construct SKS waves that have a frequency band of 0.1 to $0.3 \mathrm{~Hz}$. Finally, the SKS splitting parameters are determined by the cross-correlation method (Menke and Levin, 2003). Since the SKS splitting parameters depend on back-azimuth given the presence of low-symmetry component of the elastic tensor or tilted hexagonal symmetry axis (Becker et al., 2006b), the code averages all the fast azimuths and delay times at each station measured by rotating the elastic tensors around the vertical axis for $360^{\circ}$ with an interval of $2^{\circ}$, which is equivalent to rotating the back-azimuth. The resultant mean fast azimuth and delay time represent the geometry of SKS splitting at that station.

\section{Results}

In this section, we present the geodynamic model with mantle flow, the predicted seismic anisotropy at depths, and synthetic SWS measurements at stations where observations are available. By comparing the prediction with the observed anisotropy, we provide an explanation for the origin of the seismic anisotropy at various places across the study region.

\subsection{Different proxies for seismic anisotropy}

Various proxies have been used to represent the orientation of seismic anisotropy, including mantle velocity (e.g. Zandt and Humphreys, 2008; Assumpção et al., 2011), infinite strain axis (ISA) (e.g. Conrad et al., 2007; Conrad and Behn, 2010), the longest axis of finite strain ellipsoid (FSE) (e.g. Becker et al., 2003), and LPO predicted by fabric development models (Becker et al., 2006a, 2006b; Faccenda et al., 2008; Faccenda and Capitanio, 2013; Becker et al., 2014).

However, these proxies use different assumptions and may be inconsistent with each other. To show the differences, we compare the four different proxies at $200 \mathrm{~km}$ depth (Fig. 4) computed from the same geodynamic model with a plate reconstruction of Müller et al. (2008). Although all four proxies show some consistencies in their overall patterns, they also show important differences (Fig. 4). For example, below the Nazca Plate and west of central Andes, the orientations of the proxies are noticeably different, where LPO orientates along the east-west direction (Fig. 4d), velocity and FSE have a clear north-south component (Fig. 4a, c), and ISA shows somewhat random orientations (Fig. 4b). A similar conclusion can be drawn for the Amazonian craton: while both velocity and ISA have large values, FSE and LPO show little anisotropy, consistent with the lack of internal deformation within strong cratonic roots. 


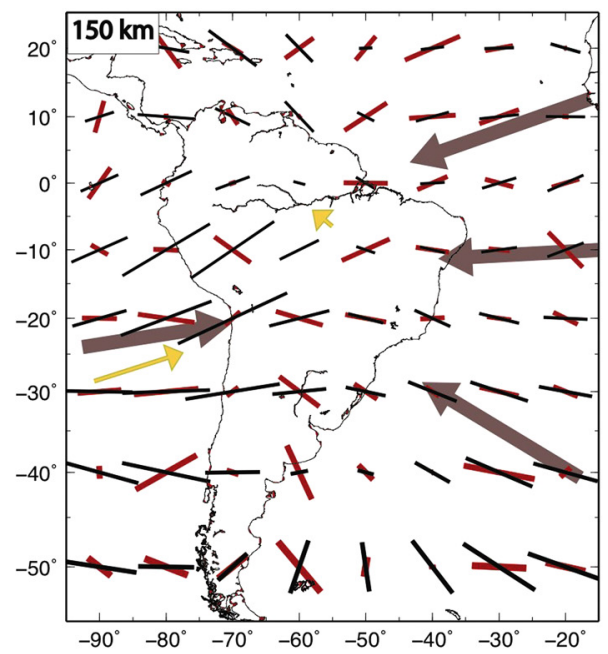

C

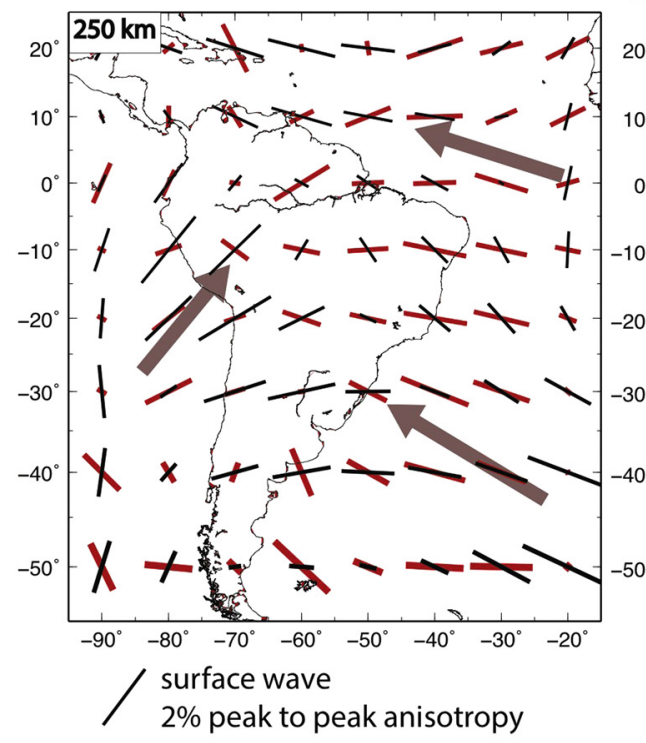

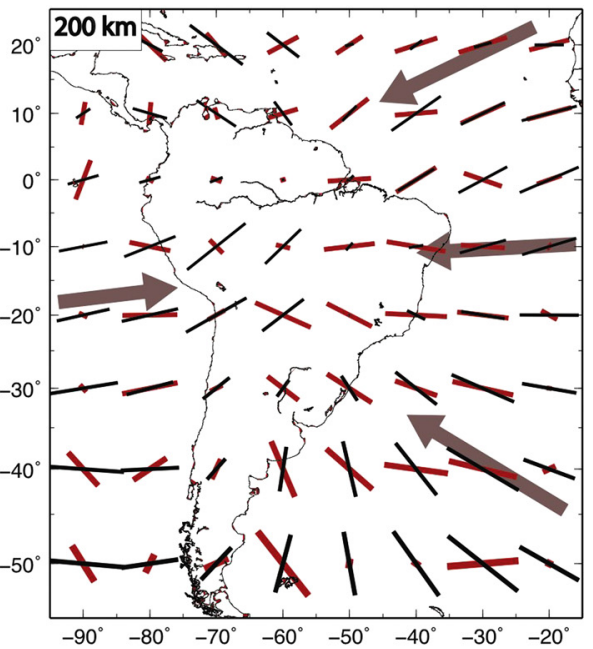

d

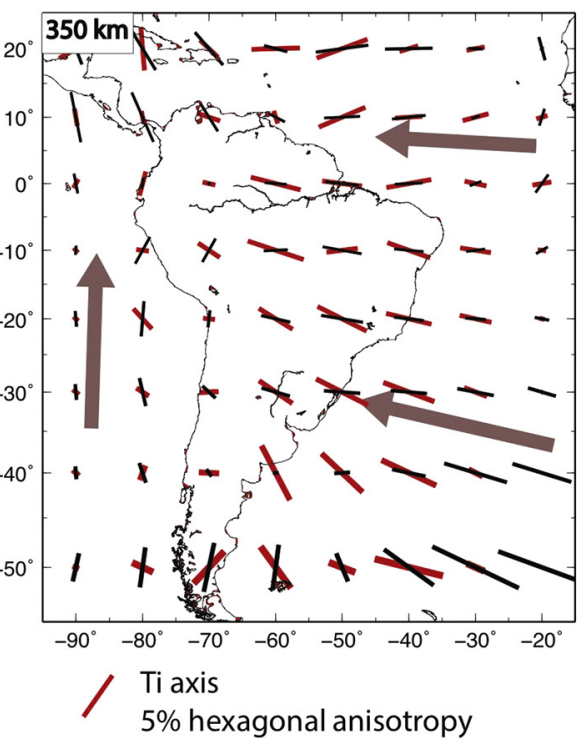

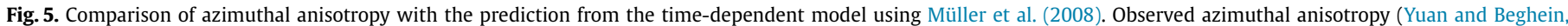

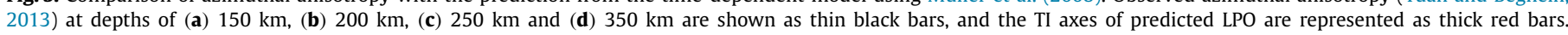

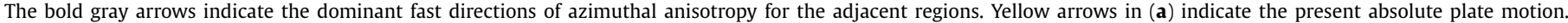
(For interpretation of the references to color in this figure legend, the reader is referred to the web version of this article.)

It is understandable that the velocity proxy is oversimplified, since formation of LPO depends on velocity gradient rather than velocity (Ribe, 1992; Kaminski et al., 2004). ISA cannot represent LPO in the regime of complex and rapidly varying mantle flow, because it does not consider the flow history (Kaminski and Ribe, 2002; Conrad et al., 2007). Furthermore, dynamic recrystallization accelerates the alignment of olivine $\mathrm{A}$ axis with the maximum stretch direction (Faccenda and Capitanio, 2013); enstatite decreases the strength of anisotropy as its slow axis aligns with the fast axis of olivine (Ribe, 1992; Kaminski et al., 2004). The fact that DRexS incorporates these processes should yield more accurate LPO than that approximated by FSE. Therefore, we use LPO (represented by TI axes) for further analysis.

\subsection{Surface-wave anisotropy}

Surface wave studies have revealed significant azimuthal anisotropy in the upper mantle above the transition zone (Debayle et al., 2005; Debayle and Ricard, 2013; Yuan and Beghein, 2013; Schaeffer et al., 2016). Here, we investigate the origin of the upper mantle anisotropy using an observationally constrained mantle flow model with the plate reconstruction of Müller et al. (2008) (Hu et al., 2016). Using the TI axes as the proxy, we derive the flow-induced LPO at different depths (Fig. 5). Overall, the predicted LPO matches the surface wave anisotropy (Yuan and Beghein, 2013) quite well at all depths. Degraded fits occur near the model boundaries due to artificial return flow and within western South America where orogeny- and subduction-related deformation and metasomatism may be important. This validates our attempt to understand seismic anisotropy using realistic geodynamic models.

Several interesting observations emerge from comparison of the azimuthal anisotropy with the predicted LPO (Fig. 5). First, at 150 and $200 \mathrm{~km}$ depths, the orientation of azimuthal anisotropy from Nazca converges with that from Atlantic, forming a large radiating pattern emanating from the South American continent (bold arrows in Fig. 5a, b). This anisotropy geometry is also observed in other surface wave anisotropy studies (Debayle et al., 2005; Schaeffer et al., 2016). This radiation pattern over the South America Plate is inconsistent with mantle flow dominated by the absolute plate motion that moves largely in one direction (e.g., Assumpção et al., 2011). Second, a continuous counter-clockwise 


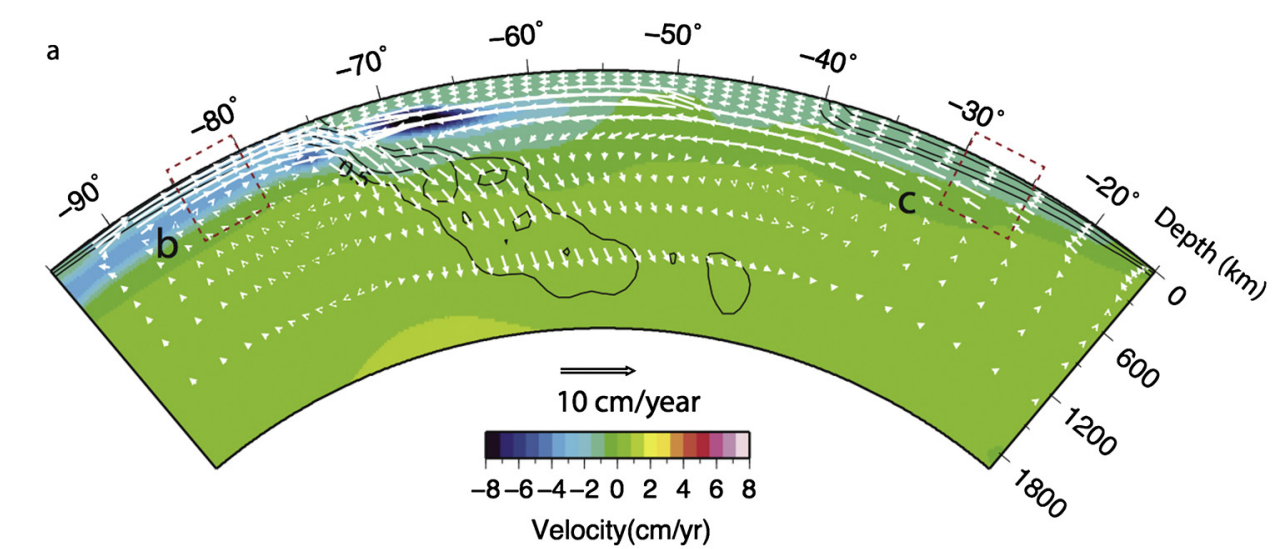

b

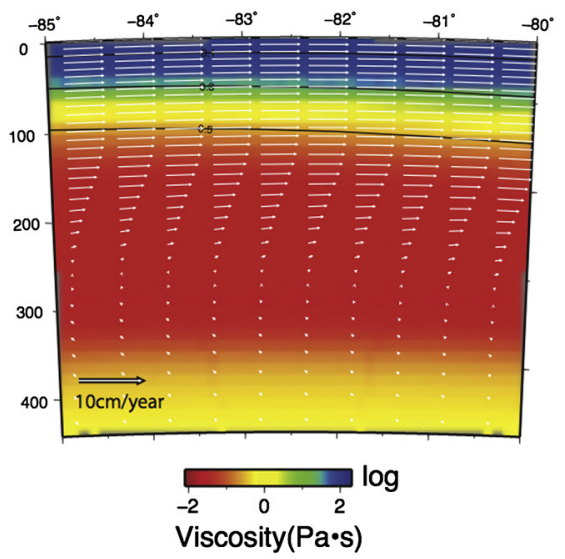

C

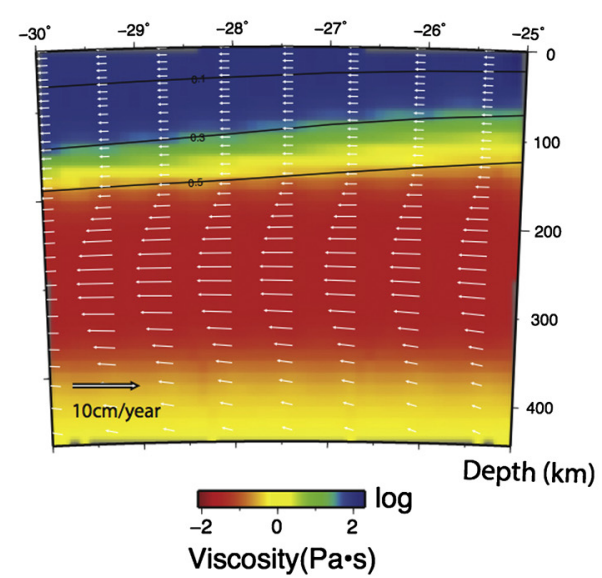

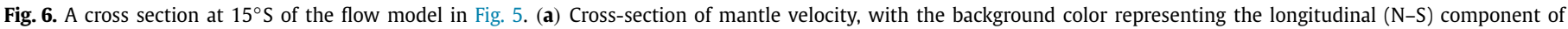

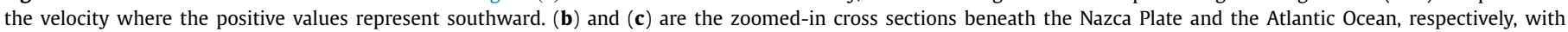
the background color showing viscosity. For all the panels, white arrows represent the velocity components within the vertical plan.

rotation of anisotropy orientation occurs from 150 to $350 \mathrm{~km}$ depths beneath the Nazca Plate, where the shallower east-west direction rotates to a deeper north-south direction (Fig. 5b, c, d). The shallower azimuthal anisotropy largely follows the absolute motion of the Nazca Plate, while the deeper anisotropy becomes orthogonal to plate motion (Fig. 1).

The prominent radiating anisotropy pattern could be naturally explained using the subduction-induced poloidal mantle flow (Fig. S4). Beneath the study region, we find a prominent westward converging asthenospheric channel flow originated from the Atlantic Ridge to the South American subduction zone, and an eastward plate-driven flow beneath the down-going Nazca plate. The former represents a typical Poiseuille flow converging toward the Andes (Fig. 6a, c), driven by the lateral pressure gradient above the concaved Nazca slab (Hu et al., 2016). The latter is a Couette flow due to the viscous entrainment from the subducting oceanic plate (Fig. 6b). These plate-scale poloidal flow fields form the radiating pattern of azimuthal anisotropy (Fig. 5). The fact that this pattern only extends to $\sim 250 \mathrm{~km}$ depth (Fig. 5) may reflect the change of poloidal velocity direction due to the increasing viscosity and different mantle buoyancy at greater depth (Fig. 2c). It is worth noting that the continental-scale asthenosphere flow is perturbed by the strong cratonic roots within the continent and the secondary slab at the Antilles subduction zone, whose effects on seismic anisotropy is discussed later.

The depth-varying mantle flow field also explains the observed transition of azimuthal anisotropy beneath the Nazca Plate. At shallow depth $(<200 \mathrm{~km})$, mantle deformation is dominated by the eastward Couette flow due to Nazca subduction (Fig. S4a, b), which leads to the east-west oriented fast direction (Fig. 5a, b).
At greater depth $(>200 \mathrm{~km})$, the trench-parallel toroidal flow and extension (Long and Silver, 2008; Faccenda and Capitanio, 2012) beneath the retreating Nazca slab becomes dominant (Fig. S4c, d), resulting in the north-south oriented anisotropy (Fig. 5c, d). However, this trench-parallel flow is of broad scale and asymmetric below the northern and southern half of the South American trench (Fig. S4). This is because, first, the slab (and the associated trench) geometry is asymmetric with a more curved shape in the northern side (Figs. 1 and 2); second, the northern half of the subduction zone has accumulated more slab material (Fig. 2a) at depths, which generates a stronger downward pull, drawing the mantle toward the north (Figs. 5 and S4).

These observations confirm the dominant role of the downgoing slab in generating the observed seismic anisotropy. As discussed above, the overall pattern of seismic anisotropy is controlled by the geometry of the slab instead of the absolute plate motion. To further validate this conclusion, we performed another geodynamic model that incorporates a different plate reconstruction (Müller et al., 2016). In this model, the South American Plate moves toward west-southwest at present (Fig. S5g-i), as is opposed to the northwest motion in Müller et al. (2008) (Fig. 5). And the velocity of Nazca Plate rotates clockwise from east-northeast in Müller et al. (2008) to east direction in Müller et al. (2016). In the new model, the depth-dependent flow and anisotropy below South America remains largely invariant (Figs. S5g-i and S6g-i vs. Figs. 5 and S4). The passive asthenosphere flow at $150 \mathrm{~km}$ depth below Nazca is slightly influenced by the plate motion (Fig. S4 vs. Fig. S6g-i), but it is not distinguishable from the predicted azimuthal anisotropy (Fig. 5 vs. Fig. S5g-i). This suggests that the present-day plate motion plays a minor role in defining the az- 


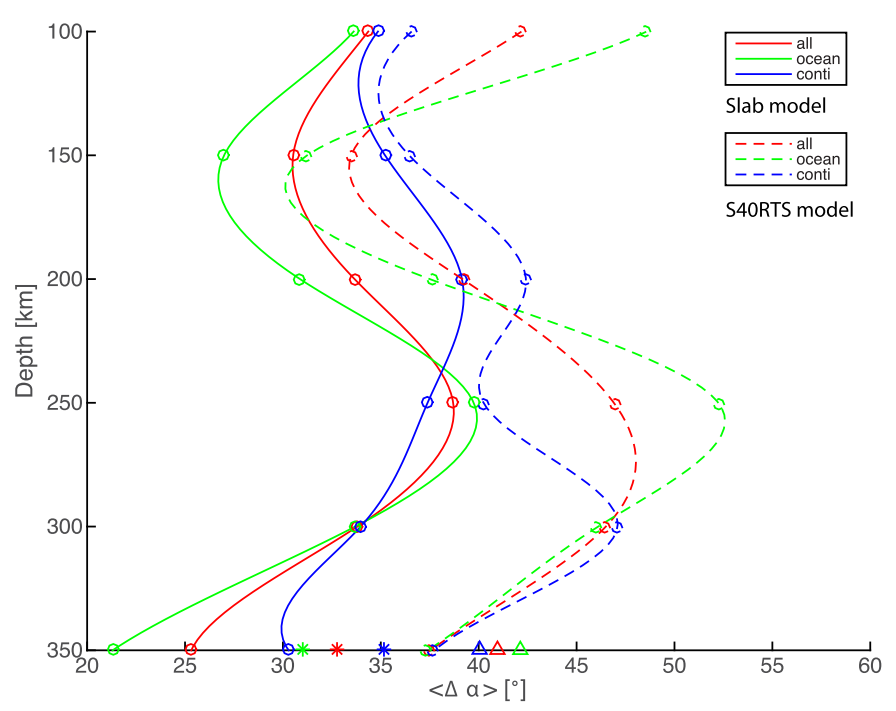

Fig. 7. Misfit between the observed and predicted azimuthal anisotropy for two different geodynamic models. Solid lines show the misfit for the time-dependent slab model with Müller et al. (2008), while dashed lines show the misfit for the instantaneous tomography (S40RTS)-based model. Green, blue and red lines represent the horizontal average for oceanic regions, continental regions and the entire model region, respectively. Stars and triangles with different colors show the volumetric average of misfit for different regions of the slab and tomography-based models, respectively. (For interpretation of the references to color in this figure legend, the reader is referred to the web version of this article.)

imuthal anisotropy in the mantle. For the rest of the paper, we will focus on one of these models, given their overall similarity.

Another way to demonstrate the dominant role of the slab in generating mantle flow is to compare the time-dependent slab model (Figs. 5 and S4) with an instantaneous model that is based on a buoyancy structure converted from seismic tomography such as S40RTS (Ritsema et al., 2011) (Figs. S5a-c and S6a-c) or SMEAN (Becker and Boschi, 2002) (Figs. S5d-f and S6d-f). Since predictions from the two tomography-based models are similar, we only compare the S40RTS model with the slab model for the variation of misfit with depth (Fig. 7). The fit to azimuthal anisotropy from the S40RTS model show a noticeable degradation at all depths (Fig. 7). The average misfit within the upper mantle beneath the entire region increases from $32.5^{\circ}$ for the slab model to $41^{\circ}$ for the S40RTS model; the misfit for oceanic regions degrades from $30.5^{\circ}$ to $42^{\circ}$. Here, we emphasize that the slab model has done a good job fitting the observation, given the low lateral resolution of surface-wave anisotropy. In fact, most poor fits occur near the boundaries of the model, due to edge effects of the regional model used here (Fig. 5).

In contrast, the tomography-based models have a relatively poor fit even far away from the boundaries (Fig. S5). This is likely due to the fact that these global tomography models do not accurately capture the slab structure (Fig. 3a, b) as that in the slab model (Fig. 3c). More importantly, the fast anomalies beneath the eastern South American Plate (outlined in Fig. 3a) are converted to high density structures in this calculation, similar to previous assumption of convective downwelling (King and Ritsema, 2000); these local convection patterns destroy the large-scale Poiseuille channel flow excited by the Nazca slab, and thus degrade the fit to seismic anisotropy. Therefore, an important conclusion is that these south Atlantic fast anomalies should have close-to-neutral buoyancy, implying a compositional instead of thermal origin. We suggest that future studies are needed to better evaluate their dynamic properties and tectonic implication. By comparing these models, we suggest that the slab plays a predominant role in shaping the pattern of azimuthal anisotropy.

\subsection{Shear wave splitting}

Relative to the azimuthal anisotropy, shear wave splitting (SWS) data provide a higher lateral resolution. The calculated synthetic SWS remarkably matches the observed data compiled by Becker et al. (2012) (Fig. 8), except for some regions along the subduction zone where the fit is marginally good. This is likely due to the presence of other anisotropy sources not considered in this study, such as B-type olivine fabric or LPO of strongly anisotropic hydrous phases in the wet cold nose of the mantle wedge (Jung and Karato, 2001; Karato et al., 2008), as well as fossil fabrics, hydrated normal faults and laminated structures within the subducting slab (Faccenda et al., 2008; Sun et al., 2014). Here, we will focus on regions to the east of the Nazca-South America trench (Figs. 8 and 9).

\subsubsection{SWS at the Caribbean-South American Plate margin}

The tectonic setting of Caribbean-South American Plate margin is quite complex. To the east, the oceanic part of South American Plate is subducting beneath the Caribbean Plate at the Antilles subduction zone (Fig. 8). To the west, the Nazca Plate and Cocos Plate are subducting beneath South America and Caribbean Plates (Müller et al., 2008, 2016). The relative motion of Caribbean and South America created the San Sebastian-El Pilar right lateral strike-slip system (Fig. 8) along the plate margin (Pérez et al., 2001). Slightly to the south of this margin, the root of the Amazonian Craton extends to at least $200 \mathrm{~km}$ depth (Ritsema et al., 2011). The observed SWS demonstrates an overall east-west orientation along this margin, while trench-parallel SWS dominates the Antilles subduction zone on the eastern side of the Caribbean Plate (Figs. 1, 8 and 9).

These observed SWS patterns are well reproduced in the slab models (Fig. 9b, c), with the best-fit one being the time-dependent model based on Müller et al. (2016). By examining the mantle flow in the upper mantle (Figs. S6g-i), we find that the large-scale asthenospheric flow converging toward the subducting Nazca slab is locally diverted by the slab below the Antilles trench, resulting in a strong focused east-west asthenosphere flow with large velocity gradient below this region (Figs. S6g-i; black arrows in Fig. 9c). The predicted east-west SWS orientation in this region strongly resembles observation (Fig. 9). This suggests the Antilles slab plays a key role in generating the observed SWS pattern in the region.

This conclusion can be further verified by comparing the instantaneous models that are based on either the predicted present slab structure (Fig. 9b) or derived from seismic tomography (Fig. 9a and Fig. S7b). The prediction for SWS from the tomography-based models is significantly worse than that from the slab model. This is mainly due to the fact that these global tomography models do not capture the slab structure surrounding the Caribbean Plate (Fig. 3), while the slab model closely resemble the slab structure revealed by regional tomography models (e.g. Benthem et al., 2013). However, compared with the time-dependent slab model (Fig. 9c), the instantaneous slab model has a notably worse fit (Fig. 9b), which suggests that the past mantle flow should be taken into account in complex tectonic settings.

Interestingly, we find the effect of Amazonian Craton is minor in the formation of the observed east-west SWS pattern in the region, which contradicts to earlier studies (Assumpção et al., 2011; Miller and Becker, 2012). This is revealed by the comparison of the best-fit model with another model that only includes a $100 \mathrm{~km}$ thick uniform continent without any cratonic roots (Fig. 8). We find the two models produce equally good SWS predictions (Fig. 8) in the plate margin. We notice that the velocity fields at the asthenospheric depths in this region are very similar with or without the cratons, suggesting the large-scale asthenosphere flow is mainly di- 


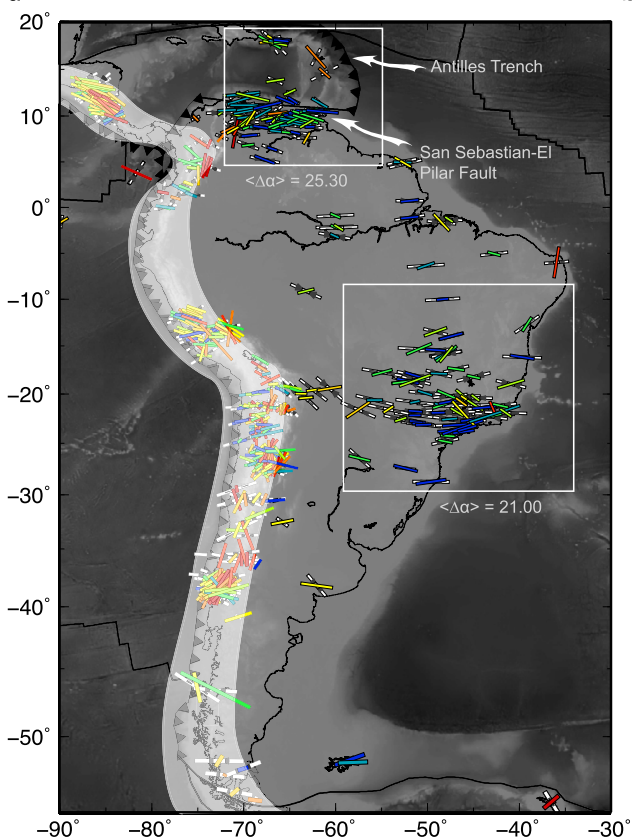

b

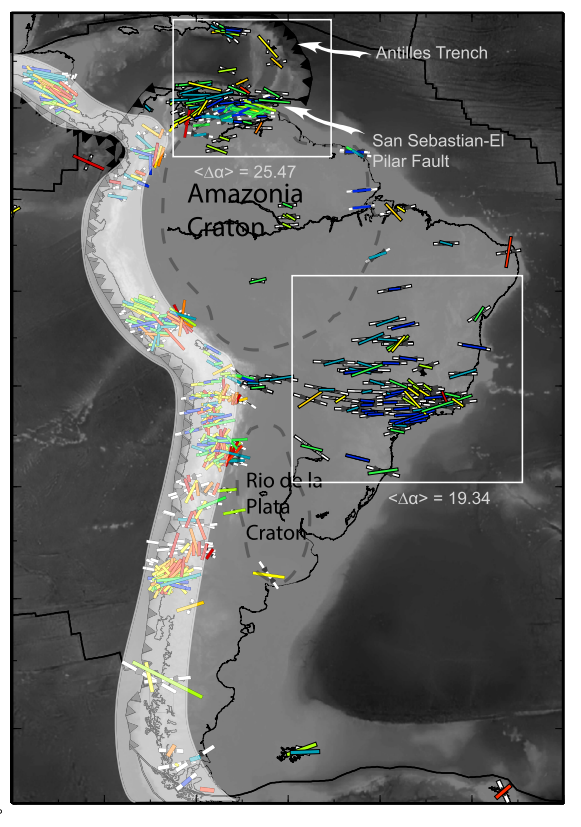

C

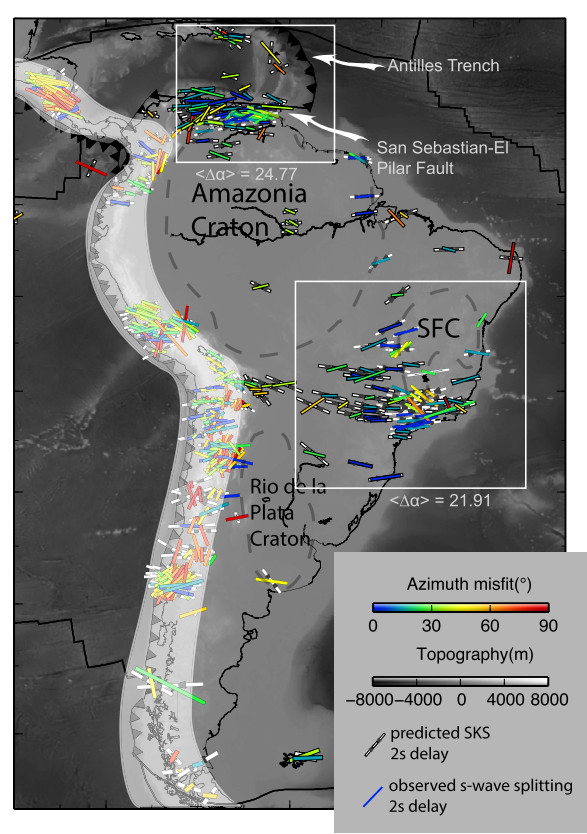

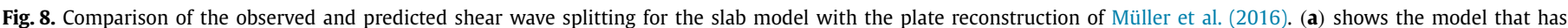

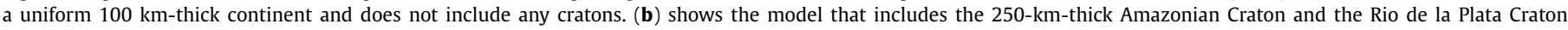

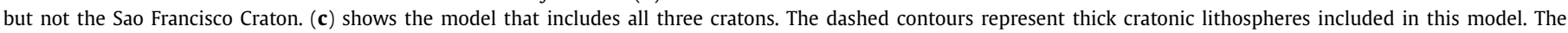

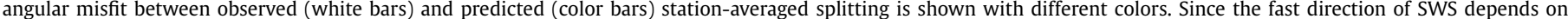

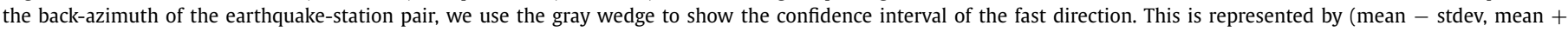

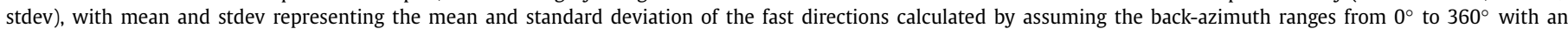

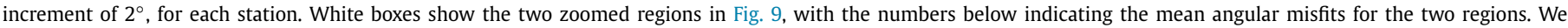
refer to Miller and Becker (2012) for the format of this figure and Fig. 9.
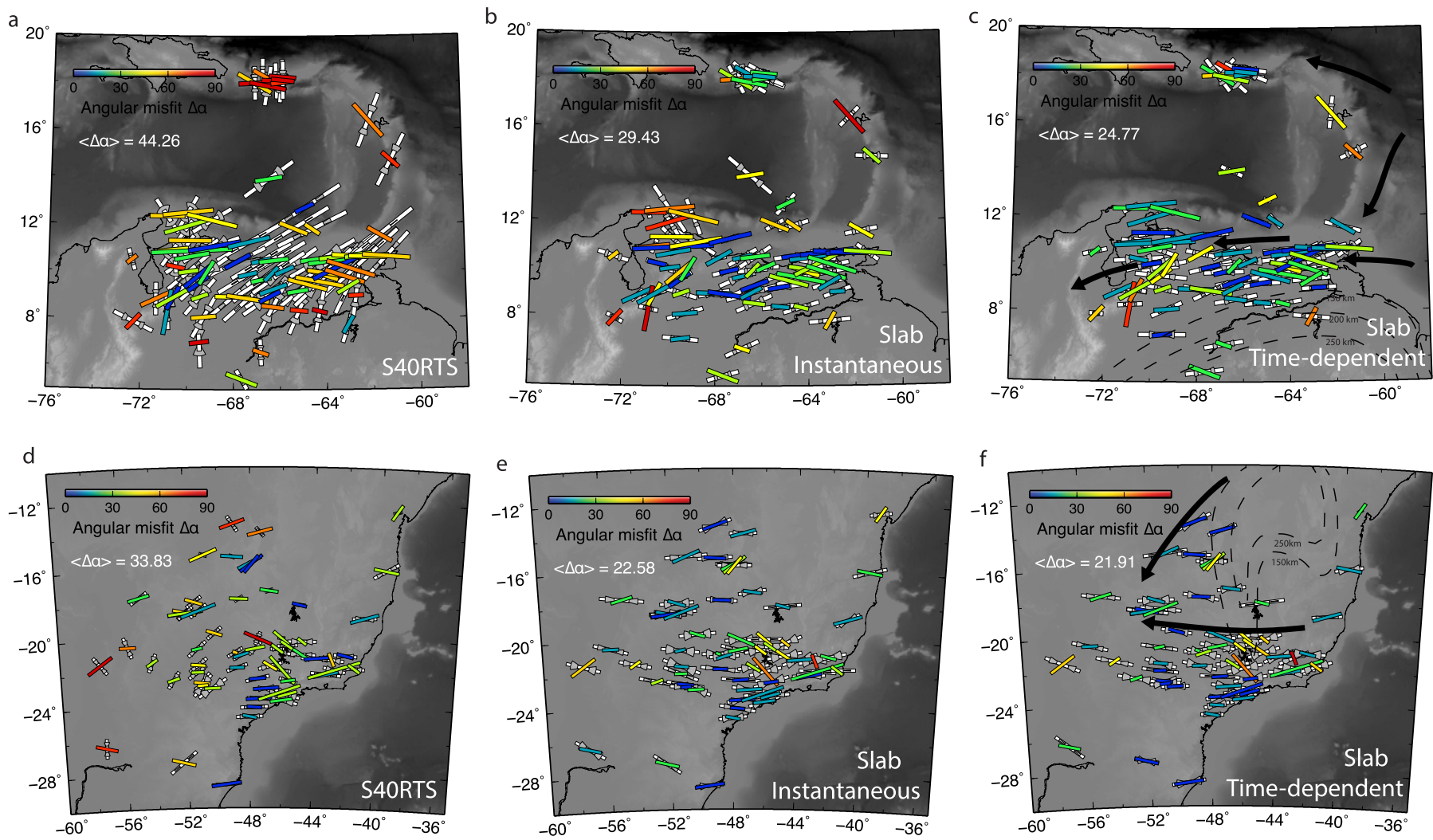

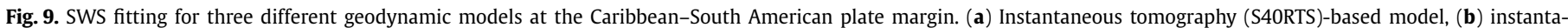

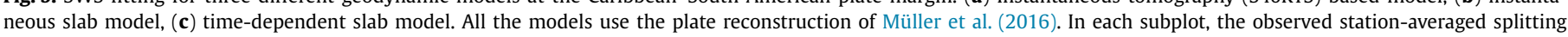

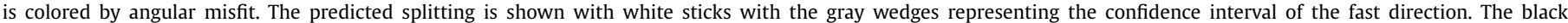
lines in (c) delineate the proposed flow direction. (d-f) Same as (a-c), but for southeast Brazil. 
verted by the secondary slab at the Antilles trench rather than the thick cratonic root in the south.

\subsubsection{SWS in southeast Brazil}

The tectonic setting of southeast Brazil is relatively simple due to its location at a passive margin. However, the relative contributions on SWS from cratonic root modulation (Figs. 1 and 8) and that from deeper mantle convection remain debated (Conrad et al., 2007; Assumpção et al., 2011). Another potential uncertainty is the contribution of fossil anisotropy from within the continental lithosphere (James and Assumpção, 1996; Marone and Romanowicz, 2007; Yuan and Beghein, 2013).

The SWS measurements in southeast Brazil demonstrate a clear local convergence from east to west (Figs. 1, 8 and 9). This observation is well reproduced in both slab models (Fig. 9e, f) with a regional average angular misfit of $\sim 22^{\circ}$, indicating the dominance of mantle flow over fossil lithospheric anisotropy in defining SWS, although the fossil anisotropy may explain local variations of SWS at a wavelength $<100 \mathrm{~km}$. We also notice that the SWS measurements are best reproduced with a thin SFC lithosphere (Fig. 8b). The geometry and thickness of this small craton slightly affect the flow pattern (Fig. S6g-i) and SWS prediction (Fig. 8b vs. Fig. 8c), with the thin-craton model producing a regionally averaged misfit at $\sim 19^{\circ}$ (Fig. 8 b), while that with a thick craton producing a larger misfit at $\sim 22^{\circ}$ (Fig. 8c). This suggests that the un-modulated asthenosphere flow can well explain the SWS, while a thick SFC lithosphere degrades the fit. We suggest that the craton root of SFC is either absent or remobilized due to Cenozoic deformation.

More insights arise from comparing different models (Fig. 9d-f). The fact that both the time-dependent slab model and the instantaneous slab model well predict the regional SWS pattern (Fig. 9e and Fig. 9f) implies that anisotropy in simple tectonic settings can be well approximated by the present mantle flow, as suggested by Conrad et al. (2007). In contrast, the tomography-based model produces a notably poorer prediction with an average misfit of $\sim 34^{\circ}$ (Fig. 9d), which is likely due to the assumed negative buoyancy of the fast anomalies underneath and thus local convection patterns, as discussed earlier. This is further confirmed in the calculation using SMEAN, which is smoother than S40RTS (Fig. 3a vs. Fig. 3b), resulting in improved orientations of predicted SWS (Fig. S7a vs. Fig. S7b). We emphasize that this does not support SMEAN as a better tomography image, since its apparent smoothness is due to lack of resolving power. Instead, this reinforces our earlier conclusion on the existence of compositional anomalies below the southern Atlantic margin. While further tuning the viscosity and density in such tomography-based calculations may improve the fit as earlier studies implied (e.g., Becker et al., 2014), changes in these model parameters, especially viscosity, are unlikely to satisfy the time-dependent subduction history from this study. Therefore, we suggest that estimation of mantle flow using tomography images is not a straightforward exercise.

\section{Discussion and conclusion}

In this study, we investigate the origin of seismic anisotropy in South America using data-oriented geodynamic models (Fig. 2). These models reveal the dominant role of subduction-induced mantle flow in generating the observed azimuthal anisotropy (Yuan and Beghein, 2013) (Fig. 5) and shear wave splitting (Becker et al., 2012) (Figs. 8 and 9). Comparatively, other tectonic factors, including absolute plate motion, fossil lithospheric anisotropy, and cratonic root diverting flow, play small to negligible roles in causing the observed anisotropy in South America. We also find that mantle flow estimated by converting tomography images to buoyancy as traditionally done cannot accurately reproduce the pattern of seismic anisotropy, due to both its poor representation of slab geometry and the uncertain nature of non-slab seismic anomalies.

Furthermore, our results reveal two different flow regimes for the development of mantle mineral fabrics: seismic anisotropy below an active subducting plate usually follows the Couette flow drive by absolute plate motion, while that below an overriding plate is more subject to the slab-induced Poiseuille flow. This finding naturally explains the observation that seismic anisotropy aligns with absolute plate motions in the Australian Plate (Debayle et al., 2005) and plates within the Pacific Ocean (Smith et al., 2004; Becker et al., 2014), since all these plates represent subducting plates during the Cenozoic (Müller et al., 2016).

In comparison, mantle deformation beneath an overriding plate, such as South America, strongly relies on the past evolution and resulting geometry of the subducting slab. In South America, the upper mantle flow converges toward the concaved Nazca slab to the west (Figs. 5 and S4). Consequently, the pattern of seismic anisotropy may deviate significantly from the recent plate motion. Another example is North America, where the observed anisotropy is sub-parallel to the absolute plate motion (Vinnik et al., 1992; Fouch et al., 2000; Marone and Romanowicz, 2007). Although North America has been an overriding plate since the Mesozoic, subduction along its west coast is close to an end, and the young subducting slab beneath the Pacific Northwest is highly segmented (Liu and Stegman, 2011; Burdick et al., 2008; Sigloch, 2011; Schmandt and Lin, 2014). Relative to the massive and continuous Nazca slab (Fig. 2), the slab below North America probably no long forms a large-scale Poiseuille flow in the asthenosphere. Consequently, mantle deformation due to the plate motion plays an important role in generating the largely east-west oriented seismic anisotropy below central and eastern North America (Vinnik et al., 1992; Fouch et al., 2000; Marone and Romanowicz, 2007).

The large-scale Poiseuille flow beneath an overriding continent also sheds light on the mechanism of plate motion. In South America, the fast motion of the large-scale asthenosphere flow exerts an overall westward drag on the above lithosphere, which should contribute to the westward drift of the South American Plate (Fig. 6). This scenario implies that the lithosphere and asthenosphere are likely coupled, consistent with the "basal drag" hypothesis (Gurnis and Torsvik, 1994; Alvarez, 2010; Becker and Faccenna, 2011; Dal Zilio et al., 2017). However, we emphasize that the asthenosphere flow may deviate from the absolute plate motion locally, as the latter is the manifestation of the net "basal drag" from the asthenosphere beneath the entire plate (Fig. 6).

Our models further demonstrate that cratons have small effects in SWS formation: in southeast Brazil, models with a thin Sao Franciscan Craton better fit observation, and the fit at the Caribbean-South America margin does not require a thick Amazonian Craton (Fig. 8), which contradicts the earlier conclusions, made by Assumpção et al. $(2006,2011)$ and Miller and Becker (2012), respectively. We emphasize that the cratons do change mantle flow and the individual SWS prediction at some sites, such as those within and at the southeastern edge of the Amazonian Craton (Fig. 8). However, the regional behavior of SWS does not change much. This suggests that craton modulation of mantle flow plays a minor role for SWS formation.

By simultaneously predicting the regional-scale azimuthal anisotropy and shear wave splitting in South America, these dataoriented models also promise a better understanding of finer-scale anisotropy such as that along subduction zones. Future modeling effects may focus on further addressing the sub-slab anisotropy (e.g. Lynner and Long, 2014), anisotropy in the mantle wedge (e.g. Nakajima and Hasegawa, 2004) and that within the slab (e.g. Eakin et al., 2016). It may also be necessary to further assimilate slow seismic anomalies in the current slab models, especially for regions 
near hot spots (Ito et al., 2014) and mid-ocean ridges (Li and Detrick, 2003; French et al., 2013).

\section{Acknowledgements}

L. Liu and J. Hu acknowledge the support from NSF grants EAR1554554, 1565640 and ACI-1516586. M. Faccenda acknowledges the grant Progetto di Ateneo FACCPTRAT12 from Università di Padova. Figures are prepared using the GMT software package (https://www.soest.hawaii.edu/gmt/).

\section{Appendix A. Supplementary material}

Supplementary material related to this article can be found online at http://dx.doi.org/10.1016/j.epsl.2017.04.027.

\section{References}

Alvarez, W., 2010. Protracted continental collisions argue for continental plates driven by basal traction. Earth Planet. Sci. Lett. 296 (3), 434-442.

Assumpção, M., Heintz, M., Vauchez, A., Silva, M.E., 2006. Upper mantle anisotropy in SE and Central Brazil from SKS splitting: evidence of asthenospheric flow around a cratonic keel. Earth Planet. Sci. Lett. 250 (1), 224-240.

Assumpção, M., Guarido, M., van der Lee, S., Dourado, J.C., 2011. Upper-mantle seismic anisotropy from SKS splitting in the South American stable platform: a test of asthenospheric flow models beneath the lithosphere. Lithosphere 3 (2), 173-180.

Becker, T.W., Boschi, L., 2002. A comparison of tomographic and geodynamic mantle models. Geochem. Geophys. Geosyst. 3 (1).

Becker, T.W., Kellogg, J.B., Ekström, G., O'Connell, R.J., 2003. Comparison of azimuthal seismic anisotropy from surface waves and finite strain from global mantlecirculation models. Geophys. J. Int. 155 (2), 696-714.

Becker, T.W., Chevrot, S., Schulte-Pelkum, V., Blackman, D.K., 2006a. Statistical properties of seismic anisotropy predicted by upper mantle geodynamic models. J. Geophys. Res., Solid Earth 111 (B8).

Becker, T.W., Schulte-Pelkum, V., Blackman, D.K., Kellogg, J.B., O’Connell, R.J., 2006b. Mantle flow under the western United States from shear wave splitting. Earth Planet. Sci. Lett. 247 (3), 235-251.

Becker, T.W., Faccenna, C., 2011. Mantle conveyor beneath the Tethyan collisional belt. Earth Planet. Sci. Lett. 310 (3), 453-461.

Becker, T.W., Lebedev, S., Long, M.D., 2012. On the relationship between azimuthal anisotropy from shear wave splitting and surface wave tomography. J. Geophys. Res., Solid Earth 117 (B1)

Becker, T.W., Conrad, C.P., Schaeffer, A.J., Lebedev, S., 2014. Origin of azimuthal seismic anisotropy in oceanic plates and mantle. Earth Planet. Sci. Lett. 401, 236-250.

Beghein, C., Yuan, K., Schmerr, N., Xing, Z., 2014. Changes in seismic anisotropy shed light on the nature of the Gutenberg discontinuity. Science 343 (6176), 1237-1240.

Benthem, S., Govers, R., Spakman, W., Wortel, R., 2013. Tectonic evolution and mantle structure of the Caribbean. J. Geophys. Res., Solid Earth 118 (6), 3019-3036.

Browaeys, J.T., Chevrot, S., 2004. Decomposition of the elastic tensor and geophysical applications. Geophys. J. Int. 159 (2), 667-678.

Burdick, S., Li, C., Martynov, V., Cox, T., Eakins, J., Mulder, T., van der Hilst, R.D., 2008. Upper mantle heterogeneity beneath North America from travel time tomography with global and USArray transportable array data. Seismol. Res. Lett. 79 (3), 384-392.

Chevrot, S., 2000. Multichannel analysis of shear wave splitting. J. Geophys. Res. Solid Earth 105 (B9), 21579-21590.

Conrad, C.P., Behn, M.D., Silver, P.G., 2007. Global mantle flow and the development of seismic anisotropy: differences between the oceanic and continental upper mantle. J. Geophys. Res., Solid Earth 112 (B7).

Conrad, C.P., Behn, M.D., 2010. Constraints on lithosphere net rotation and asthenospheric viscosity from global mantle flow models and seismic anisotropy. Geochem. Geophys. Geosyst. 11 (5).

Dal Zilio, L., Faccenda, M., Capitanio, F.A., 2017. The role of deep subduction in supercontinent breakup. Tectonophysics. http://dx.doi.org/10.1016/j.tecto.2017. 03.006. In press.

Debayle, E., Kennett, B., Priestley, K., 2005. Global azimuthal seismic anisotropy and the unique plate-motion deformation of Australia. Nature 433 (7025), 509-512.

Debayle, E., Ricard, Y., 2013. Seismic observations of large-scale deformation at the bottom of fast-moving plates. Earth Planet. Sci. Lett. 376, 165-177.

Eakin, C.M., Long, M.D., Scire, A., Beck, S.L., Wagner, L.S., Zandt, G., Tavera, H. 2016. Internal deformation of the subducted Nazca slab inferred from seismic anisotropy. Nat. Geosci. 9 (1), 56-59.
Eken, T., Plomerová, J., Roberts, R., Vecsey, L., Babuška, V., Shomali, H., Bodvarsson, R., 2010. Seismic anisotropy of the mantle lithosphere beneath the Swedish National Seismological Network (SNSN). Tectonophysics 480 (1), 241-258.

Faccenda, M., Burlini, L., Gerya, T.V., Mainprice, D., 2008. Fault-induced seismic anisotropy by hydration in subducting oceanic plates. Nature 455 (7216), 1097-1100.

Faccenda, M., Capitanio, F.A., 2012. Development of seismic anisotropy during subduction-induced 3-D mantle flow. Geophys. Res. Lett. 39. http://dx.doi.org/ 10.1029/2012GL051988.

Faccenda, M., Capitanio, F.A., 2013. Seismic anisotropy around subduction zones: insights from three-dimensional modeling of upper mantle deformation and SKS splitting calculations. Geochem. Geophys. Geosyst. 14 (1), 243-262.

Favier, N., Chevrot, S., 2003. Sensitivity kernels for shear wave splitting in transverse isotropic media. Geophys. J. Int. 153 (1), 213-228.

Foster, K., Dueker, K., Schmandt, B., Yuan, H., 2014. A sharp cratonic lithosphereasthenosphere boundary beneath the American Midwest and its relation to mantle flow. Earth Planet. Sci. Lett. 402, 82-89.

Fouch, M.J., Fischer, K.M., Parmentier, E.M., Wysession, M.E., Clarke, T.J., 2000. Shear wave splitting, continental keels, and patterns of mantle flow. J. Geophys. Res., Solid Earth 105 (B3), 6255-6275.

French, S., Lekic, V., Romanowicz, B., 2013. Waveform tomography reveals channeled flow at the base of the oceanic asthenosphere. Science 342 (6155), 227-230.

Gung, Y., Panning, M., Romanowicz, B., 2003. Global anisotropy and the thickness of continents. Nature 422 (6933), 707-711.

Gurnis, M., Torsvik, T.H., 1994. Rapid drift of large continents during the late Precambrian and Paleozoic: paleomagnetic constraints and dynamic models. Geology 22 (11), 1023-1026.

Hasterok, D., 2013. A heat flow based cooling model for tectonic plates. Earth Planet. Sci. Lett. 361, 34-43.

Hayes, G.P., Wald, D.J., Johnson, R.L., 2012. Slab1.0: a three-dimensional model of global subduction zone geometries. J. Geophys. Res., Solid Earth 117 (B1).

Hess, H.H., 1964. Seismic anisotropy of the uppermost mantle under oceans. Nature 203 (4945), 629-631.

Höink, T., Lenardic, A., Richards, M., 2012. Depth-dependent viscosity and mantle stress amplification: implications for the role of the asthenosphere in maintaining plate tectonics. Geophys. J. Int. 191 (1), 30-41.

Hu, J., Liu, L., 2016. Abnormal seismological and magmatic processes controlled by the tearing South American flat slabs. Earth Planet. Sci. Lett. 450, 40-51.

Hu, J., Liu, L., Hermosillo, A., Zhou, Q., 2016. Simulation of late Cenozoic South American flat-slab subduction using geodynamic models with data assimilation. Earth Planet. Sci. Lett. 438, 1-13.

Ismall, W.B., Mainprice, D., 1998. An olivine fabric database: an overview of upper mantle fabrics and seismic anisotropy. Tectonophysics 296 (1), 145-157.

Ito, G., Dunn, R., Li, A., Wolfe, C.J., Gallego, A., Fu, Y., 2014. Seismic anisotropy and shear wave splitting associated with mantle plume-plate interaction. J. Geophys. Res., Solid Earth 119 (6), 4923-4937.

James, D.E., Assumpção, M., 1996. Tectonic implications of S-wave anisotropy beneath SE Brazil. Geophys. J. Int. 126 (1), 1-10.

Jung, H., Karato, S.I., 2001. Water-induced fabric transitions in olivine. Science 293 (5534), 1460-1463.

Kaminski, E., Ribe, N.M., 2001. A kinematic model for recrystallization and texture development in olivine polycrystals. Earth Planet. Sci. Lett. 189 (3), 253-267.

Kaminski, E., Ribe, N.M., 2002. Timescales for the evolution of seismic anisotropy in mantle flow. Geochem. Geophys. Geosyst. 3 (8), 1-17.

Kaminski, E., Ribe, N.M., Browaeys, J.T., 2004. D-Rex, a program for calculation of seismic anisotropy due to crystal lattice preferred orientation in the convective upper mantle. Geophys. J. Int. 158 (2), 744-752.

Karato, S.I., Jung, H., Katayama, I., Skemer, P., 2008. Geodynamic significance of seismic anisotropy of the upper mantle: new insights from laboratory studies. Annu. Rev. Earth Planet. Sci. 36, 59-95.

Kendall, J.M., Silver, P.G., 1996. Constraints from seismic anisotropy on the nature of the lowermost mantle. Nature 381 (6581), 409-412.

King, S.D., Ritsema, J., 2000. African hot spot volcanism: small-scale convection in the upper mantle beneath cratons. Science 290 (5494), 1137-1140.

Li, A., Detrick, R.S., 2003. Azimuthal anisotropy and phase velocity beneath Iceland: implication for plume-ridge interaction. Earth Planet. Sci. Lett. 214 (1), 153-165.

Lin, P.Y.P., Gaherty, J.B., Jin, G., Collins, J.A., Lizarralde, D., Evans, R.L., Hirth, G., 2016. High-resolution seismic constraints on flow dynamics in the oceanic asthenosphere. Nature 535 (7613), 538-541.

Liu, L., Stegman, D.R., 2011. Segmentation of the Farallon slab. Earth Planet. Sci. Lett. 311 (1), 1-10

Loewy, S.L., Connelly, J.N., Dalziel, I.W., 2004. An orphaned basement block: the Arequipa-Antofalla Basement of the central Andean margin of South America. Geol. Soc. Am. Bull. 116 (1-2), 171-187.

Long, M.D., van der Hilst, R.D., 2005. Estimating shear-wave splitting parameters from broadband recordings in Japan: a comparison of three methods. Bull. Seismol. Soc. Am. 95 (4), 1346-1358.

Long, M.D., Silver, P.G., 2008. The subduction zone flow field from seismic anisotropy: a global view. Science 319 (5861), 315-318.

Long, M.D., Silver, P.G., 2009. Shear wave splitting and mantle anisotropy: measurements, interpretations, and new directions. Surv. Geophys. 30 (4-5), 407-461. 
Long, M.D., Becker, T.W., 2010. Mantle dynamics and seismic anisotropy. Earth Planet. Sci. Lett. 297 (3), 341-354.

Lynner, C., Long, M.D., 2014. Sub-slab anisotropy beneath the Sumatra and circumPacific subduction zones from source-side shear wave splitting observations. Geochem. Geophys. Geosyst. 15 (6), 2262-2281.

Mainprice, D., Nicolas, A., 1989. Development of shape and lattice preferred orientations: application to the seismic anisotropy of the lower crust. J. Struct. Geol. 11 (1-2), 175-189.

Marone, F., Romanowicz, B., 2007. The depth distribution of azimuthal anisotropy in the continental upper mantle. Nature 447 (7141), 198-201.

Marquardt, H., Miyagi, L., 2015. Slab stagnation in the shallow lower mantle linked to an increase in mantle viscosity. Nat. Geosci. 8 (4), 311-314.

Menke, W., Levin, V., 2003. The cross-convolution method for interpreting SKS splitting observations, with application to one and two-layer anisotropic earth models. Geophys. J. Int. 154 (2), 379-392.

Miller, M.S., Becker, T.W., 2012. Mantle flow deflected by interactions between subducted slabs and cratonic keels. Nat. Geosci. 5 (10), 726-730.

Müller, R.D., Sdrolias, M., Gaina, C., Roest, W.R., 2008. Age, spreading rates, and spreading asymmetry of the world's ocean crust. Geochem. Geophys. Geosyst. 9 (4).

Müller, R.D., Seton, M., Zahirovic, S., Williams, S.E., Matthews, K.J., Wright, N.M., Bower, D.J., 2016. Ocean basin evolution and global-scale plate reorganization events since Pangea breakup. Annu. Rev. Earth Planet. Sci. 44 (1), 107-138.

Nakajima, J., Hasegawa, A., 2004. Shear-wave polarization anisotropy and subduction-induced flow in the mantle wedge of northeastern Japan. Earth Planet. Sci. Lett. 225 (3), 365-377.

Nicolas, A., Christensen, N.I., 1987. Formation of anisotropy in upper mantle peridotites - a review. In: Composition, Structure and Dynamics of the LithosphereAsthenosphere System, pp. 111-123.

Pérez, O.J., Bilham, R., Bendick, R., Velandia, J.R., Hernández, N., Moncayo, C., Kozuch, M., 2001. Velocity field across the southern Caribbean plate boundary and estimates of Caribbean/South-American plate motion using GPS geodesy 1994-2000. Geophys. Res. Lett. 28 (15), 2987-2990.

Ribe, N.M., 1992. On the relation between seismic anisotropy and finite strain. J. Geophys. Res., Solid Earth 97 (B6), 8737-8747.

Ritsema, J., Deuss, A., Van Heijst, H.J., Woodhouse, J.H., 2011. S40RTS: a degree-40 shear-velocity model for the mantle from new Rayleigh wave dispersion, teleseismic traveltime and normal-mode splitting function measurements. Geophys. J. Int. 184 (3), 1223-1236.

Rudolph, M.L., Lekić, V., Lithgow-Bertelloni, C., 2015. Viscosity jump in Earth's midmantle. Science 350 (6266), 1349-1352.
Schaeffer, A.J., Lebedev, S., Becker, T.W., 2016. Azimuthal seismic anisotropy in the Earth's upper mantle and the thickness of tectonic plates. Geophys. J. Int. 207 (2), 901-933.

Schmandt, B., Lin, F.C., 2014. P and S wave tomography of the mantle beneath the United States. Geophys. Res. Lett. 41 (18), 6342-6349.

Sigloch, K., 2011. Mantle provinces under North America from multifrequency P wave tomography. Geochem. Geophys. Geosyst. 12 (2).

Silver, P.G., Chan, W.W., 1991. Shear wave splitting and subcontinental mantle deformation. J. Geophys. Res., Solid Earth, 16429-16454.

Silver, P.G., 1996. Seismic anisotropy beneath the continents: probing the depths of geology. Annu. Rev. Earth Planet. Sci. 24, 385-432.

Smith, D.B., Ritzwoller, M.H., Shapiro, N.M., 2004. Stratification of anisotropy in the Pacific upper mantle. J. Geophys. Res., Solid Earth 109 (B11).

Sun, D., Miller, M.S., Agostinetti, N.P., Asimow, P.D., Li, D., 2014. High frequency seismic waves and slab structures beneath Italy. Earth Planet. Sci. Lett. 391, 212-223.

Tan, E., Choi, E., Thoutireddy, P., Gurnis, M., Aivazis, M., 2006. GeoFramework: coupling multiple models of mantle convection within a computational framework. Geochem. Geophys. Geosyst. 7 (6).

Vecsey, L., Plomerová, J., Kozlovskaya, E., Babuška, V., 2007. Shear wave splitting as a diagnostic of variable anisotropic structure of the upper mantle beneath central Fennoscandia. Tectonophysics 438 (1), 57-77.

Vecsey, L., Plomerová, J., Babuška, V., 2008. Shear-wave splitting measurementsproblems and solutions. Tectonophysics 462 (1), 178-196.

Vinnik, L.P., Makeyeva, L.I., Milev, A., Usenko, A.Y., 1992. Global patterns of azimuthal anisotropy and deformations in the continental mantle. Geophys. J. Int. 111 (3), 433-447.

Wang, X., Ni, J.F., Aster, R., Sandvol, E., Wilson, D., Sine, C., Baldridge, W.S., 2008. Shear-wave splitting and mantle flow beneath the Colorado Plateau and its boundary with the Great Basin. Bull. Seismol. Soc. Am. 98 (5), 2526-2532.

Yuan, K., Beghein, C., 2013. Seismic anisotropy changes across upper mantle phase transitions. Earth Planet. Sci. Lett. 374, 132-144.

Zandt, G., Humphreys, E., 2008. Toroidal mantle flow through the western US slab window. Geology 36 (4), 295-298.

Zhang, S., Karato, S.I., 1995. Lattice preferred orientation of olivine aggregates deformed in simple shear. Nature 375 (6534), 774-777.

Zhong, S., McNamara, A., Tan, E., Moresi, L., Gurnis, M., 2008. A benchmark study on mantle convection in a 3-D spherical shell using CitcomS. Geochem. Geophys. Geosyst. 9 (10). 